\title{
Assessment of gene promoter G-quadruplex binding and modulation by a naphthalene diimide derivative in tumor cells
}

\author{
MATTEO NADAI $^{1}$, GRAZIELLA CIMINO-REALE ${ }^{2}$, GIOVANNA SATTIN ${ }^{1}$, \\ FILIPPO DORIA $^{3}$, ELENA BUTOVSKAYA ${ }^{1}$, NADIA ZAFFARONI ${ }^{2}$, MAURO FRECCERO $^{3}$, \\ MANLIO PALUMBO ${ }^{4}$, SARA N. RICHTER ${ }^{1^{*}}$ and MARCO FOLINI ${ }^{2 *}$ \\ ${ }^{1}$ Department of Molecular Medicine, University of Padova, 35121 Padova; ${ }^{2}$ Department of Experimental \\ Oncology and Molecular Medicine, Fondazione IRCCS Istituto Nazionale dei Tumori, 20133 Milan; \\ ${ }^{3}$ Department of Organic Chemistry, University of Pavia, 27100 Pavia; ${ }^{4}$ Department of Pharmaceutical \\ and Pharmacological Sciences, University of Padova, 35131 Padova, Italy
}

Received July 21, 2014; Accepted September 3, 2014

DOI: 10.3892/ijo.2014.2723

\begin{abstract}
Naphthalene diimide (NDI) derivatives have shown high affinity for telomeric guanine (G)-quadruplexes and good antiproliferative activity in different human tumor experimental models. A trisubstituted compound (H-NDI-NMe ${ }_{2}$ ) has been reported to stabilize the telomeric G-quadruplex and to cause telomere dysfunction and downregulation of telomerase expression. We further investigated its mechanism of action by analyzing the capability of the molecule to interfere with the expression levels of oncogenes, such as MYC, telomerase reverse transcriptase (TERT), KIT and BCL2, known to bear G-quadruplex-forming sequences within their promoters, in human tumor cell lines of different histological origin. Exposure to H-NDI-NMe ${ }_{2}$ resulted in a cell type-dependent perturbation of the expression levels of the four selected genes. Biophysical and molecular analyses revealed that H-NDI-NMe bound with high affinity and effectively stabilized mainly MYC and BCL2, which share long sequences and the possibility of multiple G-quadruplex folding. The mRNA levels of both genes, but not protein amounts were affected by NDI treatment. Global gene expression analysis showed modulation of genes implicated in telomere function and mechanisms of cancer; however, G-quadruplex-mediated regulation of gene expression by H-NDI-NMe ${ }_{2}$ was largely dependent on the cell context. These data indicate that a deeper knowledge on the molecular mechanisms and biological effects of G-quadruplex
\end{abstract}

Correspondence to: Dr Sara N. Richter, Department of Molecular Medicine, University of Padua, via Gabelli 63, 35121 Padua, Italy

E-mail: sara.richter@unipd.it

*Contributed equally

Key words: G-quadruplex, naphthalene diimide, oncogene promoter, tumor cell line structures is still needed to help developing new effective anticancer agents.

\section{Introduction}

Guanine (G)-quadruplexes (G-4) are non-canonical nucleic acid conformations formed by G-rich sequences based on the formation of G-quartets, stabilized by Hoogsteen-type hydrogen bonds between $\mathrm{G}$ and by interaction with cations located between the tetrads. G-4s may assemble into stacked intra- or inter-molecular four-stranded structures, the latter being more likely to form in vivo (1). G-4s have been shown to possess an extremely high degree of polymorphism. The final adopted structure depends on several factors, including base sequence, strand orientation, loop connectivity and presence and type of cations. DNA strands in G-4 take anti-parallel, parallel, or hybrid conformations, and the nucleotide linkers between G-quartets can adopt a multitude of loop structures $(2,3)$.

These structures were initially identified in telomeres, the G-rich DNA sequence located at the ends of eukaryotic chromosomes (4), and now it is well known that putative G-4-forming sequences are present within regulatory elements (e.g., promoter, untranslated regions) or bodies of several genes, leading to the notion that G-4s may be involved in several aspects of cell biology (5-7). In this context, a bioinformatic analysis identified $\sim 370,000$ candidate sequences within the human genome that, at least theoretically, may form G-4 structures. These are frequently found in proto-oncogenes rather than in tumor suppressor genes (2). In particular, the most well structurally and functionally characterized G-4-forming sequences have been found in the promoter region of oncogenes, such as MYC, KIT, BCL2 (8). According to Brooks et al (9) it is possible to recognize one or more factors involved in each hallmark of cancer (10) the gene sequence of which may fold into a G-4. In this context, a G-rich region located at -22 and -90 nucleotides from the transcription start site within the telomerase reverse transcriptase (TERT) gene promoter has been documented to contain 12 consecutive 
G-tracts, embracing three $S P 1$ binding sites. This sequence is potentially able to fold into G-4 structures (11), the formation of which may exert an inhibitory effect on TERT promoter transcriptional activity and hence resulting in the suppression of telomerase activity.

Although the physiological role of G-4 structures still needs to be intensively investigated, a growing body of evidence suggests that such non-B conformations of DNA may represent attractive targets for broad-spectrum anticancer therapies (12). Indeed, G-4s can be induced and stabilized by small molecules generally presenting large flat aromatic moieties and cationic side chains. Treatment of cells with G-4-stabilizing compounds has been shown to alter expression of many genes harbouring such sequences $(5,9,13-16)$. To date, a diverse array of G-4 stabilizing compounds has been identified $(17,18)$. Among them, numerous tri- and tetra-substituted naphthalene diimides (NDIs) have shown high affinity for telomeric G-4s and good antiproliferative activity in different experimental human tumor models (19-24).

During development of hybrid ligand-alkylating agents, we have recently synthesized a trisubstituted naphtalendiimide compound (H-NDI-NMe ${ }_{2}$ (Fig. 1A) that displays high affinity and stabilization properties towards the human telomeric sequence (21). In addition, $\mathrm{H}-\mathrm{NDI}-\mathrm{NMe}_{2}$ was able to significantly impair melanoma cell growth by causing telomere dysfunction and inhibition of telomerase activity, likely as a consequence of its interference with the expression levels of MYC and TERT (21).

In the present study, we further investigated the mechanism of action of the $\mathrm{H}-\mathrm{NDI}-\mathrm{NMe}_{2}$ derivative. In particular, the capability of the molecule to interfere with the expression levels of genes, such as MYC, TERT, KIT and BCL2, known to bear G-4 forming sequences within their promoters, has been investigated in human tumor cell lines of different histological origin. The exposure to $\mathrm{H}-\mathrm{NDI}-\mathrm{NMe}_{2}$ resulted in a cell type-dependent perturbation of the expression levels of the four selected genes. Biophysical and molecular analyses revealed that $\mathrm{H}-\mathrm{NDI}-\mathrm{NMe}_{2}$ bound with high affinity and effectively stabilized mainly MYC and BCL2. The mRNA levels of both genes were affected by NDI treatment. Global gene expression analysis showed modulation of genes implicated in telomere function and mechanisms of cancer; however, G-4-mediated regulation of gene expression by $\mathrm{H}-\mathrm{NDI}-\mathrm{NMe}_{2}$ was largely dependent on the cell context.

\section{Materials and methods}

$\mathrm{H}-\mathrm{NDI}-\mathrm{NMe}_{2}$ synthesis. The functionalized naphthalene diimide H-NDI-NMe ${ }_{2}$ was synthesized, characterized, and purified according to a published protocol, optimized by our group (21).

Oligonucleotides. All oligonucleotides were purchased from Sigma-Aldrich S.r.l. (Milan, Italy). After an initial dilution at $1 \mathrm{mM}$ in purified water, further dilutions were carried out in the relevant buffer. The sequences of the oligonucleotides used throughout the study are reported in Table I.

Cell lines and culture conditions. Human malignant melanoma (SKMel-5) and small cell lung cancer (H69) cell lines were obtained from the American Type Culture Collection. Cells were tested for the absence of Mycoplasma every 2 weeks and authenticated by the AmpFLSTR Identifiler PCR amplification kit (PN4322288; Applied Biosystems, Monza, Italy), according to the manufacturer's instructions. Cells were maintained in the logarithmic growth phase at in $5 \% \mathrm{CO}_{2}$ at $37^{\circ} \mathrm{C}$, in separate incubators, using appropriate culture media supplemented with $10 \%$ fetal bovine serum.

Analysis of NDI cytotoxic activity. To assess the cytotoxic activity of NDI, cells were seeded at the appropriate density in 6-well plates and exposed to increasing concentrations (from 0.01 to $10 \mu \mathrm{M}$ ) of freshly dissolved compound for $48 \mathrm{~h}$. Adherent cells were then trypsinized, collected and counted in a particle counter (Coulter Counter; Coulter Electronics Ltd., Luton, UK). The drug concentrations inhibiting cell growth by $50 \%\left(\mathrm{IC}_{50}\right)$ were gauged by the cell growth inhibition curves.

Analysis of the expression levels of individual genes. Total RNA was obtained from cells either untreated or exposed to sub-toxic concentrations of H-NDI-NMe $\mathrm{N}_{2}$ by TRIzol $^{\circledR}$ reagent (15596-018; Life Technologies Italia, Monza, Italy), according to the manufacturer's instructions. cDNA was randomly primed from $0.5 \mu \mathrm{g}$ RNA and amplified using the GeneAmp RNA PCR Core kit (N8080143; Applied Biosystems), according to the manufacturer's instructions. Gene expression levels were analyzed by RT-qPCR using specific TaqMan ${ }^{\circledR}$ Assay (TERT, Ms00972656_m1; MYC, Ms00153408_m1; KIT, Hs00174029_m1; BCL2, Hs99999018_m1; Applied Biosystems). Amplifications were run on the 7900HT Fast Real-Time PCR System. Data were analyzed by SDS 2.2.2 software (Applied Biosystems) and reported as relative quantity (RQ) with respect to a calibrator sample (i.e., RNA from untreated cells) according to the $2^{-\Delta \Delta \mathrm{Ct}}$ method (25). Ribonuclase P (RNaseP control reagent, PN4316844; Applied Biosystems) was used as normalizer.

Evaluation of telomerase activity. Telomerase activity was measured on $1 \mu \mathrm{g}$ of protein by the telomeric repeat amplification protocol (TRAP) using the TRAPeze kit (S7700; Millipore S.p.A., Milan, Italy) according to manufacturer's protocol. Each reaction product was amplified in the presence of a 36-bp internal TRAP assay standard (ITAS). A TSR8 quantitation standard (which serves as a standard to estimate the amount of product extended by telomerase in a given protein extract) was included for each set of TRAP assays. PCR amplification products were then resolved by polyacrylamide gel electrophoresis and visualized by autoradiography.

Western immunoblotting. Total protein extracts were prepared according to standard methods. Protein extracts $(40 \mu \mathrm{g})$ were fractioned by SDS-PAGE and transferred onto Hybond nitrocellulose filters (RPN 303D; GE Healthcare, Milan, Italy). Filters were blocked in PBS-Tween-20, 5\% skim milk and incubated overnight with primary antibodies raised against MYC (mouse monoclonal, 1:500, ab32; Abcam, Cabridge, UK), KIT (mouse monoclonal, 1:100, sc17806; Santa Cruz Biotechnology Inc, Heidelberg, Germany), BCL2 (rabbit monoclonal, 1:1,000, no. 4223; Cell Signaling Technology, Inc., Danvers, MA, USA). The filters were then probed with secondary peroxidase-linked 
A<smiles>CN(C)CCN1C(=O)c2ccc3c4c(c(NCCc5ccc(O)c(CN(C)C)c5)cc(c24)C1=O)C(=O)N(CCN(C)C)C3=O</smiles>
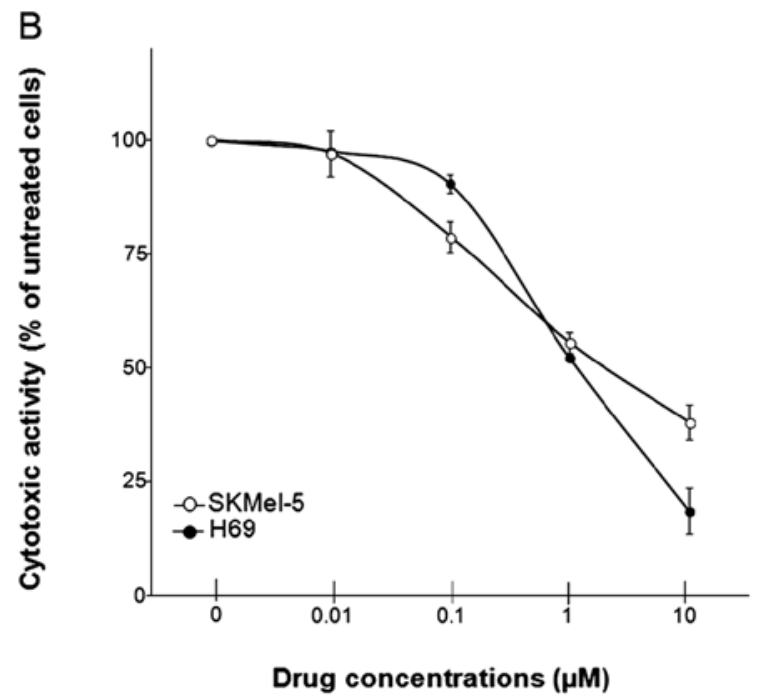

Drug concentrations $(\mu \mathrm{M})$

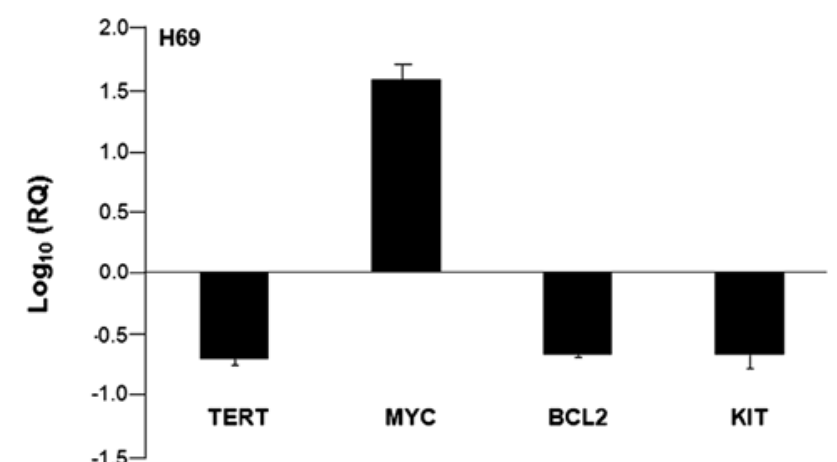

Figure 1. The naphthalene diimide (NDI) derivatives affect tumor cell viability and induce perturbation in the expression levels of selected genes. (A) Chemical structure of the H-NDI-NMe ${ }_{2}$ compound. (B) Cell growth inhibition curves of human malignant melanoma SKMel-5 (०) and small cell lung cancer H69 (•) cells obtained after a 48-h exposure to increasing concentrations of H-NDI-NMe ${ }_{2}$. Data are expressed as percentage of growing cells in NDI-treated compared to untreated cells and represent mean values \pm SD of at least three independent experiments. (C) Quantification of telomerase reverse transcriptase (TERT), $M Y C, B C L 2$ and KIT expression levels by real-time RT-PCR in SKMel-5 (left panel) and H69 cells (right panel) exposed to 0.6 and $0.4 \mu \mathrm{M}$ H-NDI-NMe ${ }_{2}$ respectively. Data are reported as $\log _{10}$-transformed relative quantity (RQ) with respect to untreated cells and represent mean values \pm SD from at least three independent experiments. n.d., not detectable.

whole antibodies (NA934V/NA931V; GE Healthcare), which were subsequently visualized by SuperSignal West Pico Chemiluminescent detection system. ACTB (mouse monoclonal, 1:1,000, ab8226; Abcam) was used on each blot to ensure equal protein loading.

FRET-melting assays. FRET competition assay was performed with FAM (6-carboxyfluorescein) 5'-end- and Tamra (6-carboxy-tetramethylrhodamine) 3'-end-labelled hTel22 oligonucleotide $(0.25 \mu \mathrm{M})$ in the presence of $0.8 \mu \mathrm{M}$ $\mathrm{H}-\mathrm{NDI}-\mathrm{NMe}_{2}$ and of G-quadruplex competitors, namely MYC, BCL2, KIT (KIT1, KIT2) and TERT (Table I). The ds26 oligomer [5'-d(CAATCGGATCGAATTCGATCCG ATTG)3'] was used as control for duplex DNA. Fluorescence melting curves were determined with a LightCycler II (Roche Diagnostics S.p.A, Monza, Italy) real-time PCR machine, using a total reaction volume of $20 \mu \mathrm{l}$, with $0.25 \mu \mathrm{M}$ of tagged oligonucleotide in a buffer containing $10 \mathrm{mM}$ lithium cacodylate $\mathrm{pH} 7.4,50 \mathrm{mM} \mathrm{KCl}$. After a first equilibration step at $30^{\circ} \mathrm{C}$ for $2 \mathrm{~min}$, a stepwise increase of $1^{\circ} \mathrm{C}$ every minute for 65 cycles to reach $95^{\circ} \mathrm{C}$ was performed and measurements were made after each cycle with excitation at $470 \mathrm{~nm}$ and detection at
$530 \mathrm{~nm}$. The melting of the G-quadruplex $+\mathrm{H}-\mathrm{NDI}-\mathrm{NMe}_{2} \mathrm{was}$ monitored alone or in the presence of various concentrations of competitor oligonucleotides. Final analysis of data was carried out using Excel and SigmaPlot software. Emission of FAM was normalized between 0 and 1 , and $\mathrm{T}_{1 / 2}$ was defined as the temperature at which the normalized emission was $0.5 . \mathrm{T}_{1 / 2}$ values were mean of 2-3 experiments and $\Delta \mathrm{T}_{1 / 2}$ was calculated as $\mathrm{T}_{1 / 2}$ difference in the presence and absence of $\mathrm{H}-\mathrm{NDI}-\mathrm{NMe}_{2}$.

SPR study. Surface plasmon resonance (SPR) measurements were performed with Biacore T100 System using streptavidin-coated sensor chips (Series $S$, Sensor chip SA) (both from GE Healthcare). The 5'-biotinylated sequences (hTel22, TERT, MYC, BCL2) (Table I) were heated to $95^{\circ} \mathrm{C}$ and annealed by slow cooling to form quadruplex in filtered and degassed $10 \mathrm{mM}$ HEPES buffer with $200 \mathrm{mM} \mathrm{KCl}$ with $0.005 \%$ surfactant Tween-20, at $\mathrm{pH}$ 7.4. Two chips were used; in each chip flow cell 1 was left blank as control to account for any signal generated owing to bulk solvent effect or any other effect not specific to the DNA interaction, which was subtracted from the signal obtained in the sample flow cells. All experiments were performed at $25^{\circ} \mathrm{C}$ using running buffer $(0.22 \mu \mathrm{m}$ 
filtered and degassed $10 \mathrm{mM}$ HEPES with $200 \mathrm{mM} \mathrm{KCl}$ and $0.005 \%$ surfactant Tween-20) at $\mathrm{pH}$ 7.4. Oligonucleotide immobilized surface was exposed to the running buffer for at least $2 \mathrm{~h}$ at a flow rate of $30 \mu 1 \mathrm{~min}^{-1}$ for attaining baseline stability. $\mathrm{H}-\mathrm{NDI}-\mathrm{NMe}_{2}$ analyte solutions at different concentrations $\left(1 \times 10^{-9}-1 \times 10^{-6} \mathrm{M}\right)$ were prepared in the running buffer and were injected (at $30 \mu 1 \mathrm{~min}^{-1}$ for $120 \mathrm{sec}$ ) in series. Following this, dissociation from the surface was monitored for $300 \mathrm{sec}$ in running buffer. Regeneration was performed with $10 \mathrm{mM}$ glycine. Analysis of the binding sensorgrams was carried out using 1:1 binding sites model in the BIA evaluation software 2.0.3 (GE Healthcare). Experiments were carried out in triplicates and the standard error was calculated.

$C D$ analysis. Circular dichroism (CD) experiments were performed on a Jasco J-810 spectropolarimeter (Jasco Europe S.r.l., Milan, Italy) equipped with a NESLAB temperature controller (Thermo Fisher Scientific, Milan, Italy) and interfaced to a PC100. A quartz cuvette with $5 \mathrm{~mm}$ path length was used for spectra recorded from 230 to $350 \mathrm{~nm}$ at $2 \mathrm{~nm}$ bandwidth, $0.1 \mathrm{~nm}$ step size, and $4 \mathrm{sec}$ time per point. The reported spectrum of each sample represents the average of two scans. Observed ellipticities were converted to mean residue ellipticity $(\theta)=\operatorname{deg~} \mathrm{x} \mathrm{cm}^{2} \mathrm{x} \mathrm{dmol}^{-1}$ (molar ellipticity). The oligomers were diluted from stock to the final concentration $(4 \mu \mathrm{M})$ in Li cacodylate buffer $(10 \mathrm{mM}, \mathrm{pH} 7.4)$ with $50 \mathrm{mM} \mathrm{KCl}$ and then annealed by heating at $95^{\circ} \mathrm{C}$ for $5 \mathrm{~min}$, gradually cooled to room temperature, and measured after $24 \mathrm{~h}$. H-NDI-NMe ${ }_{2}$ was added at $16 \mu \mathrm{M}$ final concentration.

For thermal unfolding, CD spectra were recorded from 20 to $95^{\circ} \mathrm{C}$, with temperature increase of $5^{\circ} \mathrm{C}$, and processed as above. $\mathrm{T}_{\mathrm{m}}$ values were calculated according to the van't Hoff equation, applied for a two state transition from a folded to unfolded state, assuming that the heat capacity of the folded and unfolded states are equal (26).

Binding stoichiometry was determined by the continuous variation method (Job plot). Solutions of MYC or BCL2 and $\mathrm{H}-\mathrm{NDI}-\mathrm{NMe}_{2}$ were mixed in different proportions maintaining a total concentration of DNA + H-NDI-NMe ${ }_{2}$ of $10 \mu \mathrm{M}$. The mole fractions for DNA/(DNA + H-NDI-NMe $)_{2}$ were 0.12 , $0.15,0.20,0.27,0.31,0.35,0.37,0.46,0.50,0.55,0.60$. The mole fraction of the DNA was plotted against the molar ellipticity at $290 \mathrm{~nm}$ of the DNA + H-NDI-NMe ${ }_{2}$ complex. In the plot, the mole fraction of the DNA at which the molar ellipticity of the DNA + H-NDI-NMe ${ }_{2}$ complex is maximum, gives the stoichiometry of the complex. The number of H-NDI-NMe ${ }_{2}$ binding sites is equivalent to $(1-\mathrm{x}) / \mathrm{x}$, where $\mathrm{x}$ is the DNA fraction at the intersection of the two fitting straight lines. All samples were allowed to equilibrate overnight. A buffer baseline was collected in the same cuvette and subtracted from the sample spectra.

Taq polymerase stop assay. Primer was labelled with $\left[\gamma^{-32} \mathrm{P}\right]-$ ATP (PerkinElmer, Milan, Italy) using T4 polynucleotide kinase (Thermo Fisher Scientific) for $30 \mathrm{~min}$ at $37^{\circ} \mathrm{C}$ and purified with Illustra MicroSpin G-25 Column (GE Healthcare). 5 '-end-labeled primer (final concentration $70 \mathrm{nM}$ ) [primer MYC Taq 5'-d(ATCGATCGCTTCTCGTCCGCTAACC TTC)-3'; primer BCL2 Taq 5'-d(ATCGATCGCTTCTCGTC AGCCCCGCT)-3'] was annealed to the template bearing the 
sequence of interest (final concentration $36 \mathrm{nM}$, in lithium cacodylate buffer, $10 \mathrm{mM}, \mathrm{pH}$ 7.4) [MYC wt Taq template 5'-d(CTGGGGAGGGTGGGGAGGGTGGGGAAGGTTAG

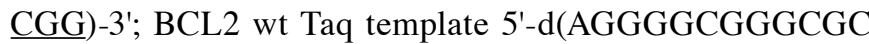
GGGAGGAAGGGGGCGGGAGCGGGGCTG)-3'] or a scrambled non-G-quadruplex forming sequence [MYC scrambled Taq template 5'-d(CTGGAAAGAGTGAAGAGA GAGTGAAGAAGGTTAGCGG)-3'; BCL2 scrambled Taq template 5'-d(AGAAGCGAAAGCGAAAGGAAGAAGAAA A AGCGGGGCTG)-3']. Underlined bases indicate complementary bases in the primer and template strands. Where appropriate, $\mathrm{KCl}$ was added and the mixture was let annealed by heating at $95^{\circ} \mathrm{C}$ for $5 \mathrm{~min}$, gradually cooled to room temperature, and incubated at $4^{\circ} \mathrm{C}$ overnight. Mixtures were incubated with NDI for $20 \mathrm{~min}$ at room temperature in the presence of $100 \mathrm{mM} \mathrm{KCl}$. Primer extension was conducted with $2 \mathrm{U}$ of AmpliTaq Gold DNA Polymerase (2 U/reaction; Applied Biosystems, Carlsbad, CA, USA) at $47^{\circ} \mathrm{C}$ for $30 \mathrm{~min}$. The reaction was stopped by $\mathrm{EtOH}$ precipitation and primer extension products were separated on a $12 \%$ denaturing gel and visualized by phosphorimaging (Typhoon FLA 9000; GE Healthcare).

Gene expression analysis. Total RNA was isolated from untreated and NDI-treated cells using Qiagen RNeasy Mini kit (74104; Qiagen S.r.l., Milan, Italy) and digested with $20 \mathrm{U}$ RNase-free DNase I (79254; Qiagen S.r.1.), according to the manufacturer's instructions. The expression levels of $28 \mathrm{key}$ genes related to telomere replication and maintenance (TRM) and of 92 genes associated with the molecular mechanisms of cancer were assessed using TaqMan ${ }^{\circledR}$ Arrays (PN4418832 and PN4418806; Applied Biosystems). The expression values were assessed by RT-qPCR according to the manufacturer's instructions. Modulation of gene expression in treated compared to untreated cells was assessed by the $2^{-\Delta \Delta \mathrm{Ct}}$ method. The $18 \mathrm{~S}$ housekeeping gene present in each array was used as normalizer. Differentially expressed genes in treated vs. untreated cells were sorted based on $\mathrm{P}<0.05$ (Student's t-test) and considered up- or downregulated by set a fold-change of 1.5 as cut-off.

\section{Results and Discussion}

Effects of $\mathrm{H}-\mathrm{NDI}-\mathrm{NMe}_{2}$ on the expression levels of genes known to be affected following G-4 stabilization. Short-term cytotoxic activity of $\mathrm{H}-\mathrm{NDI}-\mathrm{NMe}_{2}$ (Fig. 1A) was first tested against two cancer cell lines of different histological origin, namely human malignant melanoma SKMel-5 and small cell lung cancer H69 cells. Results showed a dose-dependent inhibition of cell growth in both experimental models after a 48-h exposure to increasing drug concentrations (Fig. 1B). The compound was active in the micromolar range and no significant differences in the sensitivity to $\mathrm{H}-\mathrm{NDI}-\mathrm{NMe}_{2}$ were observed between the two cell lines, as revealed by the $\mathrm{IC}_{50}$ values $(1.75 \pm 0.18 \mu \mathrm{M}$ and $1.18 \pm 0.04 \mu \mathrm{M}$ for SKMel-5 and H69 cells, respectively) obtained from at least three independent experiments.

As previously reported, $\mathrm{H}-\mathrm{NDI}-\mathrm{NMe}_{2}$ derivative exerted an inhibitory effect on the catalytic activity of telomerase in SKMel-5 cells that seemed to primarily occur as a consequence of drug-mediated decrease of TERT and MYC mRNA expression levels (21). To further investigate the capability of the compound to interfere with the expression of selected genes, we focused on TERT, MYC, KIT and BCL2, which have been reported to undergo inhibition following ligand-mediated stabilization of G-4 structures within their promoters (8).

In this context, dose-response curves were instrumental to guide the choice of $\mathrm{H}-\mathrm{NDI}-\mathrm{NMe}_{2}$ concentration to be used for the analysis of gene expression levels. A 48-h exposure of cells to sub-toxic concentrations of the ligand (corresponding to $\sim 1 / 3$ of the relative $\mathrm{IC}_{50}$ values) resulted in a cell type-dependent modulation in the expression levels of selected genes (Fig. 1C). Real-time RT-PCR data showed a marked reduction of TERT expression levels (Fig. 1C), which was more pronounced in H69 (RQ, 0.20 \pm 0.02 ) compared to SKMel-5 cells (RQ, 0.44 \pm 0.002$)$. A downregulation of BCL2 expression levels (Fig. 1C) was observed in both cell lines. Again, such a decrease was markedly pronounced in $\mathrm{H} 69$ with respect to melanoma cells (RQ, $0.21 \pm 0.01$ and $0.73 \pm 0.05$, respectively). In addition, small cell lung cancer cells were also characterized by a pronounced decrease in the expression levels of KIT (RQ, $0.22 \pm 0.06$ ), which in turn was not detectable in melanoma cells (Fig. 1C).

Taking into account that MYC is involved, at least in part, in the transcriptional control of TERT, its gene expression levels were assessed in both NDI-treated cells. In keeping with our previous findings (21), the exposure of SKMel-5 to $\mathrm{H}-\mathrm{NDI}-\mathrm{NMe}_{2}$ resulted in a decrease, though minimal, of MYC expression levels (RQ, 0.89 \pm 0.08 ). Conversely, a pronounced increase in the level of MYC gene expression (Fig. 1C) was observed in $\mathrm{H} 69$ cells following treatment with $\mathrm{H}-\mathrm{NDI}-\mathrm{NMe}_{2}$ (RQ, 38.2 \pm 8.4 ). It should be taken into account that the extent to which MYC expression levels were increased in H69 cells upon NDI treatment may simply reflect the fact that its mRNA basal expression levels were almost undetectable in untreated cells. By real-time RT-PCR, MYC was detectable at a threshold cycle $(\mathrm{Ct})$ of $\sim 35$. This evidence indeed accounted for the magnification of the differences in the gene expression levels observed in treated $(\mathrm{Ct}=29)$ vs. untreated samples following the use of the $2^{-\Delta \Delta \mathrm{Ct}}$ method. To note, however, the G-4-mediated increase in MYC expression levels has already been reported. Polyamines (i.e., spermidine and spermine) may stabilize and favor quadruplex formation over duplex within the nuclease hypersensitive

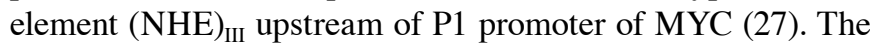
exposure of HeLa cells to increasing concentration of spermidine and spermine resulted in a concentration-dependent increase of MYC transcript levels and abrogated the inhibitory effect of TMPyP4, a non-selective porphyrin-based G-4 ligand, on MYC transcription, suggesting that both polyamines and TMPyP4 stabilize MYC G-4, but cause opposite effects on gene transcription (27). It has been proposed that polyamines induce a structural transition of MYC G-4 toward a transcriptionally active motif (probably the parallel conformer), with likely distinctive molecular recognition properties for transcription factors, which drives MYC expression. Conversely, TMPyP4 does not induce any structural change in MYC G-4 conformation, but it simply masks or competes with the binding of transcription factors, thus resulting in the inhibition of gene transcription (27). Similarly, the perturbation of the equilibrium between quadruplex and duplex structures of MYC induced by a locked nucleic acid trap, which favors duplex over quadruplex 

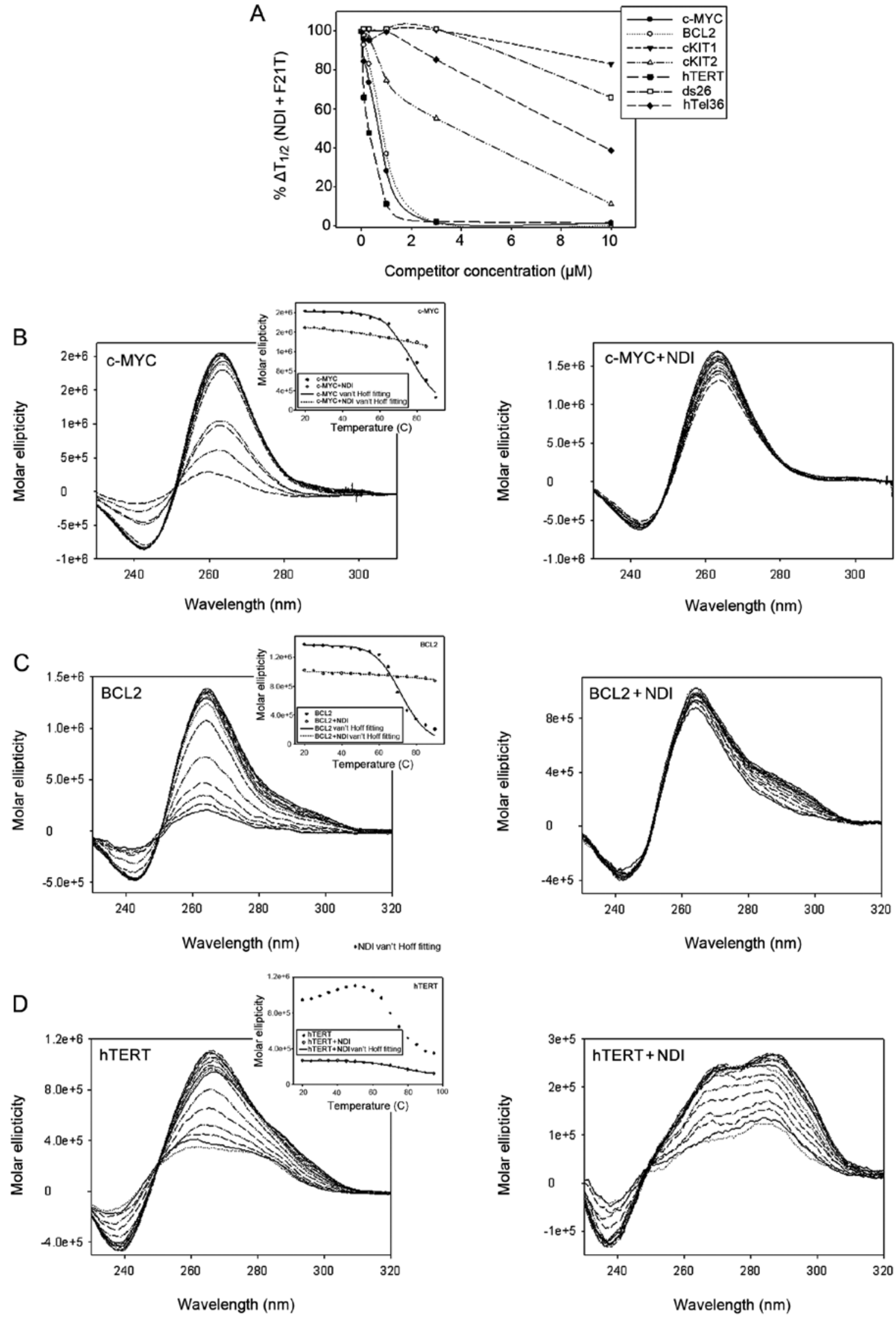

Figure 2. Chemo-physical characterization of naphthalene diimide (NDI)-mediated guanine (G)-4 stabilization within the promoter regions of selected genes. (A) FRET competition assay. The FAM-Tamra dual labelled hTel22 oligonucleotide $(0.25 \mu \mathrm{M})$ was incubated with H-NDI-NMe ${ }_{2}$ and with the G-quadruplex competitors, MYC, BCL2, KIT (KIT1, KIT2) and telomerase reverse transcriptase (TERT). Ds26 was used as control for duplex DNA. T $_{1 / 2}$ was defined as the temperature at which the normalized emission was 0.5 . $T_{1 / 2}$ values were mean of 2-3 experiments and $\Delta T_{1 / 2}$ was calculated as $T_{1 / 2}$ difference in the presence and absence of $\mathrm{H}-\mathrm{NDI}-\mathrm{NMe}_{2}$. (B) MYC, (C) BCL2, (D) TERT oligonucleotide spectra recorded at increasing temperature (25-95 $\left.{ }^{\circ} \mathrm{C}\right)$ in the absence (left panels) and presence (right panel) of $\mathrm{H}-\mathrm{NDI}-\mathrm{NMe}_{2}(16 \mu \mathrm{M})$. In the insets, molar ellipticity at the peak wavelength was plotted against temperature and fitted with the van't Hoff equation, where possible. 
Table II. Properties of $\mathrm{H}-\mathrm{NDI}-\mathrm{NMe}_{2}$ binding and stabilization towards G-4 oncogene promoters and the control telomeric sequence hTel22.

\begin{tabular}{|c|c|c|c|c|c|}
\hline \multirow[t]{2}{*}{ G-4 DNA } & \multicolumn{2}{|c|}{ FRET CC $_{50}$ competition $(\mu \mathrm{M})$} & \multicolumn{2}{|c|}{$\mathrm{CD} \mathrm{T}_{\mathrm{m}}\left({ }^{\circ} \mathrm{C}, 260 \mathrm{~nm}\right)$} & \multirow[t]{2}{*}{$\mathrm{CD} \Delta \mathrm{T}_{\mathrm{m}}\left({ }^{\circ} \mathrm{C}\right)$} \\
\hline & $50 \mathrm{mM} \mathrm{K}^{+}$ & $150 \mathrm{mM} \mathrm{K}^{+}$ & no NDI & NDI $(16 \mu \mathrm{M})$ & \\
\hline hTel22 & - & - & $66.1 \pm 1.2$ & $84.9 \pm 0.3$ & 18.8 \\
\hline MYC & $0.21 \pm 0.01$ & $0.51 \pm 0.03$ & $84.0 \pm 0.4$ & $>100$ & $>16$ \\
\hline BCL2 & $0.46 \pm 0.02$ & $0.64 \pm 0.06$ & $72.0 \pm 0.7$ & $>100$ & $>28$ \\
\hline KIT1 & $>10$ & $>10$ & $72.8 \pm 1.3$ & $88.0 \pm 0.5$ & 15.2 \\
\hline KIT2 & $2.0 \pm 0.8$ & $3.1 \pm 0.08$ & $79.0 \pm 1.1$ & $97.8 \pm 1.7$ & 18.8 \\
\hline TERT & $0.08 \pm 0.01$ & $0.20 \pm 0.03$ & $65.4 \pm 0.9$ & $77.6 \pm 1.2$ & 12.2 \\
\hline dsDNA & $>10$ & $>10$ & n.d. & n.d. & n.d. \\
\hline
\end{tabular}

$\mathrm{CD}$, circular dichroism; TERT, telomerase reverse transcriptase; n.d., not detectable.

structure, resulted in the silencing of MYC expression (28). Moreover, the cellular nucleic-acid-binding protein (CNBP) promotes the formation of a parallel G-4 within the $\mathrm{NHE}_{\mathrm{III}}$ region of MYC and favors the activation of gene transcription in vitro (29). A competition between CNBP and TMPyP4 has been documented. This evidence highlights the prevalent role of CNBP in inducing structural transitions that favors parallel G-4 conformers over those stimulated by TMPyP4, even when these measurements were carried out at CNBP:TMPyP4 molar ratio of 1:10 (29). Of note, the basic N-terminal region of CNBP shares biochemical features with polyamines and it is required for the promotion of G-4 folding (29).

$\mathrm{H}-\mathrm{NDI}-\mathrm{NMe}_{2}$ preferentially binds and greatly stabilizes $G$-quadruplexes within the promoter of MYC and BCL2. The binding properties of $\mathrm{H}-\mathrm{NDI}-\mathrm{NMe}_{2}$ were investigated towards a panel of G-4-forming oligonucleotides, corresponding to the promoter regions of MYC, BCL2, KIT (KIT1 and KIT2) and TERT (Table I) and compared to the binding properties against the telomeric sequence (hTel22) (Table I) which have been previously acquired (21).

Initially, a FRET competition experiment was employed to identify the G-4 sequences displaying high affinity for H-NDI-NMe $e_{2}$. The FAM/TAMRA-labelled hTel22 sequence $(0.25 \mu \mathrm{M})$ (Table I) was incubated with $\mathrm{H}-\mathrm{NDI}-\mathrm{NMe}_{2}$, in the presence of 50 or $150 \mathrm{mM} \mathrm{K}^{+}$, and exposed to increasing concentrations of competitor G-4 sequences. In both salt conditions the best competing sequence was TERT, followed by MYC and BCL2. The KIT2 sequence resulted to be a poor competitor, whereas both KIT1 and dsDNA were not able to disrupt $\mathrm{H}-\mathrm{NDI}-\mathrm{NMe}_{2}$ binding to hTel22 (Table II) (Fig. 2A). Since long oligonucleotides (i.e., TERT, MYC, BCL2), likely forming multiple G-4 structures, were the best competitor sequences, a 36-bp-long telomeric sequence (hTel36) (Table I) was additionally tested. However, in this case low competition was obtained (Fig. 2A), indicating that the efficient competition observed with TERT, MYC and BCL2 was sequence specific and not simply dependent on steric features. These data were corroborated by the higher affinity constant (KD) values at $25^{\circ} \mathrm{C}$ of $\mathrm{H}-\mathrm{NDI}-\mathrm{NMe}_{2}$ towards TERT $(0.42 \pm 0.04 \mu \mathrm{M})$, MYC $(0.39 \pm 0.03 \mu \mathrm{M})$ and
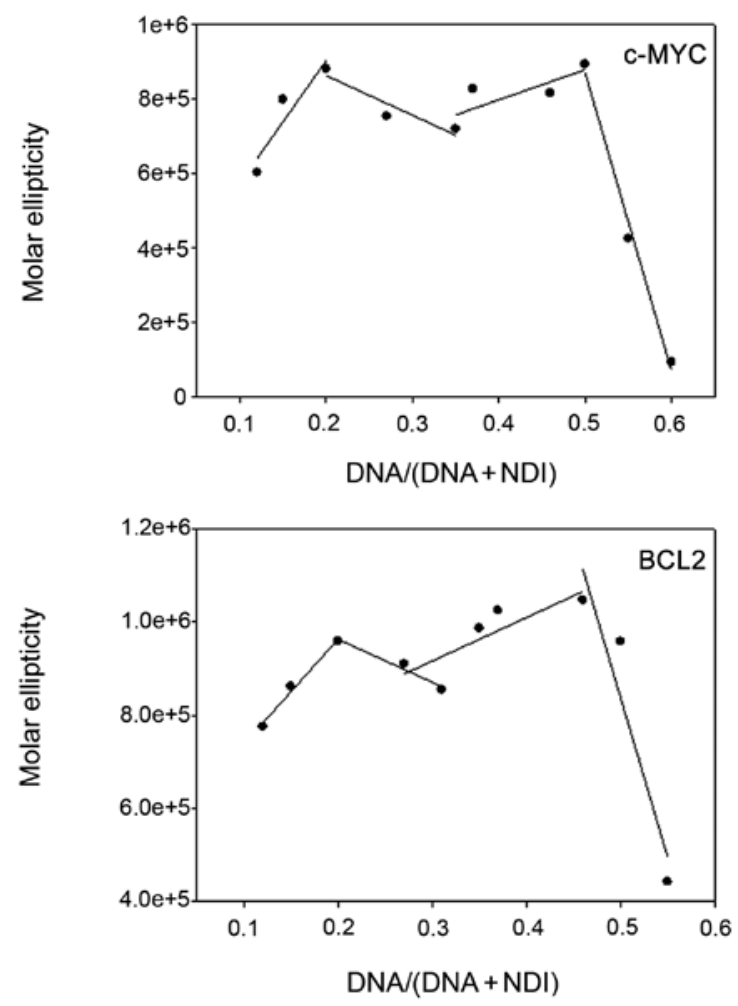

Figure 3. Stoichiometry of oligonucleotide-H-NDI-NMe ${ }_{2}$ complexes. Job plots performed with a total amount of MYC or BCL2 oligonucleotides of $10 \mu \mathrm{M}$, and varying DNA and drug proportions. The two fitting straight lines intersect at DNA fractions of 0.2 and 0.5 , which correspond to four and one molecules, respectively, of $\mathrm{H}-\mathrm{NDI}-\mathrm{NMe}_{2}$ bound to one oligonucleotide molecule.

BCL2 $(0.33 \pm 0.03 \mu \mathrm{M})$ with respect to hTel22 $(3.12 \pm 0.04 \mu \mathrm{M})$, obtained by SPR analysis.

$\mathrm{CD}$ was next employed to analyse both the stability and prevalent conformation of the G-quadruplex forming oligonucleotides in the presence of $\mathrm{H}-\mathrm{NDI}-\mathrm{NMe}_{2}$. We found that $\mathrm{H}-\mathrm{NDI}-\mathrm{NMe}_{2}$ maintained a prevalent parallel conformation in MYC, BCL2, KIT1 and KIT2 (Fig. 2B and C, and data not shown), whereas it induced a hybrid-like topology in TERT (Fig. 2D). These data are in keeping with those reported in literature and concerning the biophysical characterization 

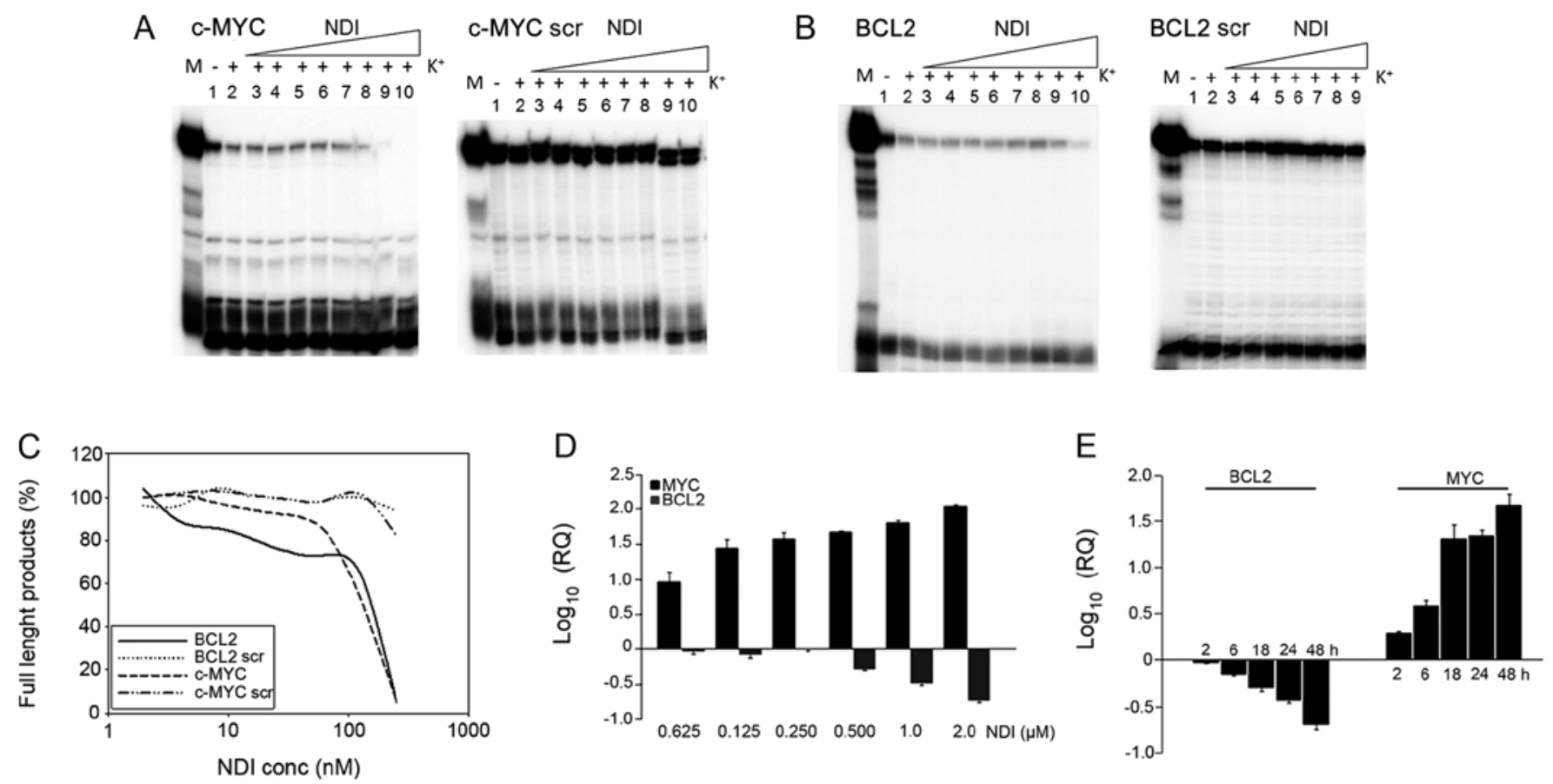

Figure 4. H-NDI-NMe - -treatment effects on MYC and BCL2 DNA and mRNA levels. Taq polymerase stop assay on (A) MYC and (B) BCL2 templates in the presence of increasing concentrations of $\mathrm{H}-\mathrm{NDI}-\mathrm{NMe}_{2}$ (lanes 3-10 or 3-9). Control lanes are the oligonucleotide templates folded in the presence (lane 2) or absence (lane 1) of $\mathrm{K}^{+} 100 \mathrm{mM}$ and treated with Taq polymerase in the absence of the naphthalene diimide (NDI). M is a marker lane that indicates position of the full-length amplified product. Scrambled oligonucleotides are control template oligonucleotides that do not form guanine (G)-4 (right panels). They were designed to contain the same base composition as the corresponding oligonucleotides, but in a different order so that G-4 could not form. (C) Quantification of full-length product bands of the gels shown in panels (A) and (B). (D) Quantification of MYC and BCL2 expression levels by real-time RT-PCR in H69

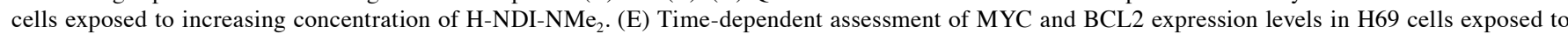
$0.4 \mu \mathrm{M} \mathrm{H}-\mathrm{NDI}-\mathrm{NMe}_{2}$. In panels (D) and (E) data are reported as $\log _{10}$-transformed relative quantity (RQ) with respect to untreated cells and represent mean values $\pm \mathrm{SD}$ from at least three independent experiments.

of G-4 conformers of the selected genes in the presence or absence of specific ligands $(11,29-31)$.

The evidence that $\mathrm{H}-\mathrm{NDI}-\mathrm{NMe}_{2}$ maintained a parallel MYC G-4 conformer deals with the observed increase in the gene expression levels in H69 cells upon NDI exposure, as also suggested by the findings that polyamines and CNBP both stimulate MYC transcriptional activity by favouring the formation of a parallel G-4 structure within the gene promoter $(26,28)$. Conversely, the well-known inhibitory activity of the cationic porphyrin TMPyP4 on MYC expression levels likely resides in the drug-mediated conformational conversion from parallel into either a parallel/anti-parallel mixture or anti-parallel-type MYC G-4 (29).

Downregulation of KIT expression levels by ligand-mediated stabilization of G-4 structures within the gene promoter have been consistently documented (32-35). Conversely, different layers of complexity have been reported regarding the G-4-forming sequences within the BCL2 promoter $(36,37)$. In fact, it has been demonstrated that BCL2 may form diverse G-4 structures with a parallel- or mixed-type conformation, the biological significance of which still need to be disclosed (31). However, the existence of G-4-forming sequences within the BCL2 promoter points towards their possible role in modulating gene expression. Depending on which G-4 conformer is predominant in vivo variable biological consequences may be expected upon stabilization by diverse ligands (37).

In addition, both MYC and BCL2 were highly stabilized by H-NDI-NMe ${ }_{2}$ binding $\left(\mathrm{T}_{\mathrm{m}}>100^{\circ} \mathrm{C}\right)$, whereas treatment of
TERT, KIT1 and KIT2 G-4-folded oligonucleotides with $\mathrm{H}-\mathrm{NDI}-\mathrm{NMe}_{2}$-treated resulted in $\mathrm{T}_{\mathrm{m}}<98^{\circ} \mathrm{C}$; these latter values are comparable to the stabilization observed with hTel22 at $260 \mathrm{~nm}$ (Table II) (21). It is noteworthy that in the case of MYC and BCL2 the molar ellipticity signal was slightly decreased upon addition of the H-NDI-NMe ${ }_{2}$ (Fig. 2B and C), whereas a remarkable decrease along with a variation in the spectral features was observed for TERT (Fig. 2D), indicating a significant destabilization of the initial G-4 topology.

Since the best bound and stabilized G-4s are long sequences within MYC and BCL2 composed of 5-6 GGG repeats that may form multiple tetraplexes, $\mathrm{H}-\mathrm{NDI}-\mathrm{NMe}_{2}$ binding stoichiometry towards these sequences was investigated by CD-monitored Job plot analysis. Results showed that a 1:1 complex was stabilized in both MYC and BCL2 sequences in the presence of high DNA/(DNA + NDI) ratios, whereas up to four NDI molecules bound to the G-4 structure, forming a stable complex at low DNA/(DNA + NDI) ratios (Fig. 3). These data are in line with the binding stoichiometry observed for hTel22 (up to four bound molecules) (21), indicating that the higher affinity of $\mathrm{H}-\mathrm{NDI}-\mathrm{NMe}_{2}$ for $\mathrm{MYC}$ and BCL2 with respect to hTel22 did not rely on the number of NDI molecules bound to the G-4.

Further evidence of MYC and BCL2 G-4 stabilization by $\mathrm{H}-\mathrm{NDI}-\mathrm{NMe}_{2}$ was provided by the Taq polymerase stop assay. Because primers were designed to anneal in part to the G-rich sequence involved in G-4 formation, inhibition of the full-length primer-extended product was expected upon G-4 


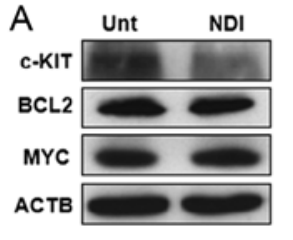

B

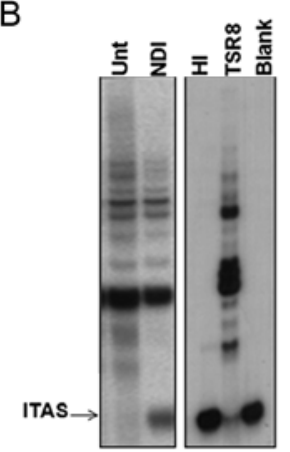

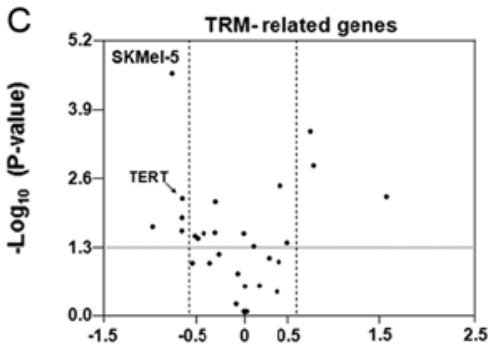
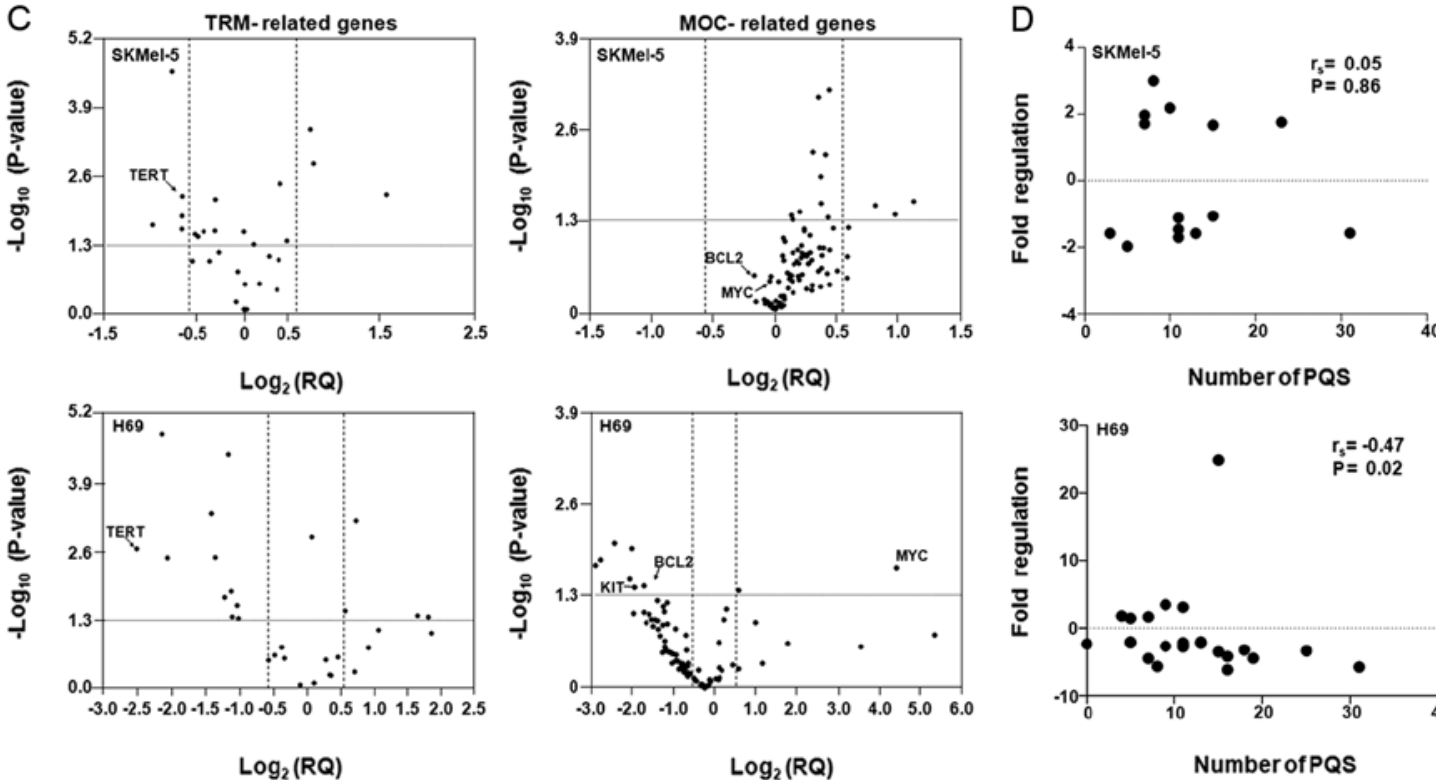

$\log _{2}(R Q)$

$\log _{2}(R Q)$

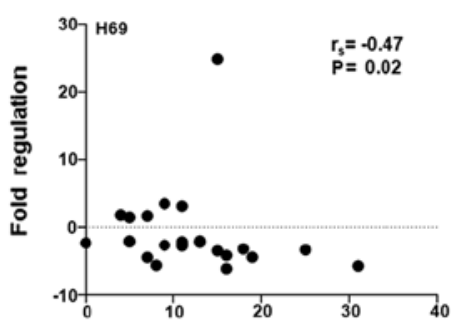

Number of PQS

Figure 5. (A) Representative immunoblotting showing the expression levels of MYC, BCL2 and KIT proteins in H69 cells after a 48-h exposure to $0.4 \mu \mathrm{M}$ $\mathrm{H}-\mathrm{NDI}-\mathrm{NMe}_{2}$. ACTB, $\beta$-actin. (B) Representative telomeric repeat amplification protocol (TRAP) assay showing the inhibition of telomerase activity in naphthalene diimide (NDI)-treated H69 cells. Unt, untreated cells; NDI, cells exposed for $48 \mathrm{~h}$ to $0.4 \mu \mathrm{M} \mathrm{H}-\mathrm{NDI}-\mathrm{NMe}_{2}$; HI, heat-inactivated sample; TSR8, quantitation standard; Blank, no protein extract. The arrow indicates the 36-bp internal TRAP assay standard (ITAS). (C) Volcano plots showing telomere replication and maintenance (TRM) and molecular mechanisms of cancer (MOC) gene expression patterns in NDI-treated SKMel-5 and H69 cells compared to untreated cells. Gene expression data have been plotted as $\log _{2}$ [relative quantity (RQ)] vs. - $\log _{10}$ (P-value) obtained from at least three independent experiments The level of statistical significance (round-dotted line, $\mathrm{P}<0.05$ ) and the cut-off (dashed line, 1.5 -fold up- or downregulation) used to identify gene differentially expressed in treated- vs. untreated cells have been indicated. (D) Analysis of the correlation between the modulation of gene expression levels and the number of putative quadruplex forming sequences (PQS) within gene promoters in SKMel-5 and H69 cells treated with NDI. $r_{s}$, Spearman's correlation coefficient.

folding. As shown in Fig. 4, the strong inherent MYC and BCL2 G-4 stability in the presence of $\mathrm{K}^{+}$partly impaired enzyme processing, even in the absence of NDI. Indeed, MYC and BCL2 full-length products were remarkably less in the wild-type compared to scrambled templates, used as controls to check for the possible G4-independent inhibition

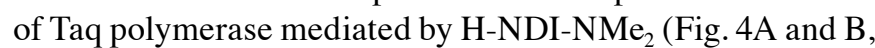
lane 2). Similarly, in the absence of $\mathrm{K}^{+}$, full-length run-offs were less abundant in wild-type than in scrambled templates (Fig. 4A and B, lane 1), even though this effect was more evident for MYC than BCL2, thus confirming the ability of the MYC sequence to fold into G-4 independently of $\mathrm{K}^{+}$. In addition, a dose-dependent inhibition of the full-length products was observed in the G-4-forming templates when the assay was performed in the presence of increasing concentrations of H-NDI-NMe ${ }_{2}$ (Fig. 4A and B, lanes 1-9/10). Interestingly, at 50 and $100 \mathrm{nM} \mathrm{H-NDI-NMe}$, no full-length product formed in MYC and BCL2, respectively (Fig. 4A-C), indicating an extremely efficient stabilization of the MYC and BCL2 G-4 topologies upon H-NDI-NMe ${ }_{2}$ binding.

This evidence was also mirrored by the concentration-dependent and the kinetics of the modulation of MYC and BCL2 mRNA expression levels (Fig. 4D and E). A dose-dependent modulation in the expression levels of both genes was observed in $\mathrm{H} 69$ cells exposed to increasing concentrations (up to $2 \mu \mathrm{M}$ ) of H-NDI-NMe ${ }_{2}$ (Fig. 4D). In addition, the increase and the decrease in MYC and BCL2 expression levels, respectively, was already appreciable in cells after a 2-h exposure to $0.4 \mu \mathrm{M}$ H-NDI-NMe ${ }_{2}$ and they ranged in a time-dependent manner up to a 48 -h exposure to the drug (Fig. 4E).
Effects of the NDI on the protein amounts of selected genes. To verify whether the NDI-mediated G-4 stabilization and the consequent modulation of mRNA expression levels resulted in perturbation in protein amounts of selected genes, further investigations were performed in H69 cell line, which showed the greatest modulation in the expression of selected genes upon exposure to H-NDI-NMe ${ }_{2}$ (Fig. 1C). Specifically, no changes in MYC and BCL2 protein amounts were evidenced by western immunoblotting in $\mathrm{H} 69$ cells after a 48 -h exposure to $0.4 \mu \mathrm{M}$ H-NDI-NMe ${ }_{2}$, whereas a pronounced decrease in KIT protein levels was observed (Fig. 5A). In addition, consistent with our previous data obtained in SKMel-5 cells (21) we observed in NDI-treated compared to untreated H69 cells a marked inhibition of telomerase activity (Fig. 5B), likely due to drug-induced reduction in TERT expression levels. We cannot exclude that the lack of correlation between the capability of H-NDI-NMe ${ }_{2}$ to stabilize G-4 structures within the promoter of the selected genes, as assessed by chemo-physical assays, and the modulation of the relative protein amounts may depend on compensatory responses activated by cells to cope with the drug action.

The NDI induces a global perturbation in gene expression. To test such a hypothesis, we investigated the gene expression profiles in both tumor cell lines following exposure to H-NDI-NMe ${ }_{2}$. Specifically, we focused on commercially available TaqMan ${ }^{\circledR}$ Array containing 28 genes related to the TRM and 92 genes associated to the molecular mechanisms of cancer (MOC). Results showed that nine out of 28 (32.1\%) TRM-related genes were significantly modulated in SKMel-5 cells (Fig. 5C): three genes, known as components of the 
Table III. The TRM- and MOC-related genes differentially expressed in NDI-treated vs. -untreated tumor cells.

\begin{tabular}{|c|c|c|c|c|c|}
\hline \multirow[b]{2}{*}{ Detector } & \multirow[b]{2}{*}{ Gene name } & \multicolumn{2}{|c|}{ Fold regulation ${ }^{\mathrm{a}}$} & \multicolumn{2}{|c|}{ No. of PQS ${ }^{b}$} \\
\hline & & SKMel-5 & H69 & EuQuad & GQRS \\
\hline \multicolumn{6}{|l|}{ TRM } \\
\hline$T E R T$ & Telomerase reverse transcriptase & -1.6 & -5.8 & 6 & 25 \\
\hline$N B N$ & Nibrin & - & -4.2 & 0 & 16 \\
\hline$H N R N P D$ & Heterogeneous nuclear ribonucleoprotein D & - & -2.0 & 0 & 13 \\
\hline$A C T B$ & Actin, $\beta$ & - & -4.5 & 7 & 12 \\
\hline TERF2 & Telomeric repeat binding factor 2 & 1.7 & - & 3 & 12 \\
\hline$G U S B$ & Glucuronidase, $\beta$ & -1.6 & -2.3 & 2 & 11 \\
\hline$R P L P O$ & Ribosomal protein, large, $\mathrm{P} 0$ & - & -2.2 & 0 & 11 \\
\hline$B 2 M$ & $\beta$-2-microglobulin & - & 3.1 & 1 & 10 \\
\hline$H N R N P F$ & Heterogeneous nuclear ribonucleoprotein $\mathrm{F}$ & - & -2.7 & 0 & 9 \\
\hline$H M B S$ & Hydroxymethylbilane synthase & -1.5 & -2.6 & 3 & 8 \\
\hline MRE11A & MRE11 meiotic recombination 11 homolog A & -1.7 & - & 3 & 8 \\
\hline$P G K 1$ & Phosphoglycerate kinase 1 & - & - & 2 & 8 \\
\hline$T E R F 2 I P$ & Telomeric repeat binding factor 2 , interacting protein & 3.0 & - & 0 & 8 \\
\hline TERF1 & Telomeric repeat binding factor (NIMA-interacting) 1 & 1.7 & 1.6 & 0 & 7 \\
\hline TFRC & Transferrin receptor $(\mathrm{p} 90, \mathrm{CD} 71)$ & - & 3.5 & 2 & 7 \\
\hline HNRNPA1 & Heterogeneous nuclear ribonucleoprotein A1 & -2.0 & -2.1 & 0 & 5 \\
\hline POT1 & POT1 protection of telomeres 1 homolog & - & 1.5 & 0 & 5 \\
\hline$R A D 50$ & RAD50 homolog & - & -2.2 & 0 & 5 \\
\hline$H N R N P A 2 B 1$ & Heterogeneous nuclear ribonucleoprotein A2/B1 & -1.6 & - & 0 & 3 \\
\hline$H N R N P A B$ & Heterogeneous nuclear ribonucleoprotein $\mathrm{A} / \mathrm{B}$ & - & -2.3 & 0 & - \\
\hline \multicolumn{6}{|l|}{ MOC } \\
\hline$H R A S$ & v-Ha-ras Harvey rat sarcoma viral oncogene homolog & - & - & 20 & 39 \\
\hline CCNE1 & Cyclin E1 & - & -6.2 & 0 & 16 \\
\hline KIT & $\begin{array}{l}\text { v-kit Hardy-Zuckerman } 4 \text { feline sarcoma viral } \\
\text { oncogene homolog }\end{array}$ & n.d. & -3.2 & 3 & 15 \\
\hline$B A X$ & BCL2-associated X protein & - & -3.5 & 0 & 15 \\
\hline$A K T 1$ & v-Akt murine thymoma viral oncogene homolog 1 & - & -3.4 & 11 & 14 \\
\hline$B I D$ & $\mathrm{BH} 3$-interacting domain death agonist & 1.8 & - & 11 & 12 \\
\hline$B C A R 1$ & Breast cancer antiestrogen resistance 1 & - & - & 5 & 12 \\
\hline$R A C 1$ & Ras-related C 3 botulinum toxin substrate 1 & - & - & 4 & 12 \\
\hline$B C L 2$ & B-cell CLL/lymphoma 2 & -1.1 & -2.8 & 0 & 11 \\
\hline$F G F 2$ & Fibroblast growth factor 2 (basic) & - & - & 3 & 10 \\
\hline$M A X$ & MYC associated factor $\mathrm{X}$ & n.d. & - & 5 & 9 \\
\hline$T G F B R 2$ & Transforming growth factor, $\beta$ receptor II & - & - & 2 & 9 \\
\hline$M Y C$ & v-MYC myelocytomatosis viral oncogene homolog & -1.1 & 24.8 & 7 & 8 \\
\hline$C D K 4$ & Cyclin-dependent kinase 4 & - & - & 6 & 8 \\
\hline$A K T 2$ & $\mathrm{v}$-Akt murine thymoma viral oncogene homolog 2 & - & - & 0 & 8 \\
\hline$P I K 3 R 1$ & Phosphoinositide-3-kinase, regulatory subunit 1 & - & - & 0 & 8 \\
\hline$F A D D$ & Fas (TNFRSF6)-associated via death domain & - & - & 5 & 7 \\
\hline$B C L 2 L 1$ & BCL2-like 1 & 2.0 & - & 0 & 7 \\
\hline$C D K N 1 A$ & Cyclin-dependent kinase inhibitor 1A (p21, Cip1) & 2.2 & - & 4 & 6 \\
\hline$C Y C S$ & Cytochrome $c$, somatic & - & -4.5 & 1 & 6 \\
\hline FOS & v-Fos FBJ murine osteosarcoma viral oncogene homolog & - & - & 4 & 5 \\
\hline FAS & Fas (TNF receptor superfamily, member 6) & - & - & 0 & 5 \\
\hline TP53 & Tumor protein $\mathrm{p} 53$ & - & 1.8 & 0 & 4 \\
\hline$C D C 42$ & Cell division cycle 42 (GTP binding protein, $25 \mathrm{kDa})$ & - & -5.7 & 5 & 3 \\
\hline
\end{tabular}

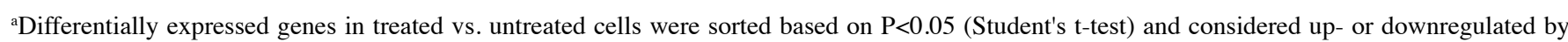
set a fold-change of 1.5 as cut-off. ${ }^{b}$ The number of putative quadruplex forming sequences (PQS) within the promoter of telomere replication and maintenance (TRM)- and molecular mechanisms of cancer (MOC)-related genes has been verified by web-based tools for predicting G-4 in nucleotide sequences: EuQuad (45) and GQRS (46). NDI, naphthalene diimide; n.d., not detectable. 
shelterin complex (TERF1, TERF2 and TER2IP) were upregulated (Table III) and six genes were downregulated. Among the down-modulated genes we found TERT, thus confirming the data obtained using single assays, as well as GUSB, HMBS, MRE11A, HNRNPAI and HNRNPA2BI (Table III). However, a more marked perturbation in gene expression was observed in NDI-treated H69 cells than in SKMel-5 cells, further corroborating our previous observation (Fig. 1). Specifically, we identified 15 out of 28 (53.6\%) differentially expressed genes in the panel of TRM-related genes in NDI-treated H69 cells compared to untreated cells. In particular, four (i.e., B2M, POTI,TERF1 and TFRC) and 11 (TERT, NBN, RAD50, HMBS, HNRNPF, HNRNPAB, HNRNPAl, HNRNPD, $A C T B, G U S B$ and $R P L P O)$ genes were found significantly up- and downregulated, respectively, in treated cells. Of note, housekeeping genes present in the array (i.e., $A C T B, G U S B$ and $R P L P O$ ) were found modulated after NDI-treatment in both cell lines. This is not surprising since all three housekeeping genes are predicted to contain one or more putative quadruplex forming sequences (PQS) within their promoter region, as evidenced by two different in silico $\mathrm{PQS}$ prediction tools (Table III).

The analysis of the expression levels of genes related to the MOC revealed only three out 92 genes (5.4\%) significantly up-modulated in NDI-treated compared to untreated SKMel-5 cells (Fig. 5C), which included $B I D, B C L 2 L 1$ and $C D K N 1 A$. Interestingly, the observed up-modulation of $C D K N I A$, which encodes for the cyclin-dependent kinase inhibitor $\mathrm{p} 21^{\mathrm{WAF} 1}$, is in keeping with our previous data showing a marked accumulation of $\mathrm{p} 21^{\mathrm{WAF} 1}$ protein in SKMel-5 cells exposed to NDI (21) or to the G-4 ligand Ant1,5 (38). Conversely, only a modest downregulation of MYC and BCL2 was observed in NDI-treated SKMel-5 cells (Table III), thus corroborating the data obtained by single gene expression assays (Fig. 1).

Similarly to TRM-related genes, the exposure of H69 cells to H-NDI-NMe ${ }_{2}$ resulted in a greater number of differentially expressed genes compared to SKMel-5 cells undergoing the same treatment (Fig. 5C). Specifically, nine out of 92 genes (9.8\%) were modulated in H69-treated cells, of which two (MYC and TP53) were found up-modulated and seven (CCNE1, $K I T, B A X, A K T 1, B C L 2, C Y C S, C D C 42)$ were markedly downregulated (Table III).

Altogether, these data show that the possible G-4-mediated regulation of gene expression is largely dependent on the cell context. Data obtained from both single assays (Fig. 1C) and array analyses (Fig. 5C) showed a lower number of genes the expression levels of which are markedly modulated upon H-NDI-NMe ${ }_{2}$ exposure in SKMel-5 compared to H69 cells. In addition, a trend toward a correlation between the number of PQS within gene promoters and the modulation of gene expression may be observed in NDI-treated H69 cells only (Fig. 5D). Moreover, the genes that have modulated expression levels in $\mathrm{H} 69$ cells upon treatment with the G-4 ligand indicate a drug-mediated perturbation in telomere architecture/function as well as a global defense response activated by cells likely in their attempt to cope with drug-induced stress.

Compelling arguments have been provided on the prominent role of G-4 structures in the modulation of gene expression (39). The first and clearest evidence of G-4 structure involved in the regulation of gene transcription came from studies on MYC. Indeed, the possibility to inhibit MYC transcription through G-4 stabilization has been actively pursued thus far in several human cancer models using specific small molecules (40).

Although G-4 structures have been primarily recognized as transcriptional repressor elements, it is now becoming clear that their formation along the genome may facilitate the maintenance of an open chromatin state, thus allowing gene transcriptional activity (29). Gene promoter regions harboring $\mathrm{PQS}$ have indeed the potential to bind a diverse array of factors that may favor or constrain gene transcription. As a consequence, the possibility of generating secondary structures, such as G-4, may influence the interaction between transcription factors and DNA, or vice versa, thus resulting in either activation or repression of gene expression. This evidence suggests that the functional consequences of G-4-interacting agents may depend on the specific mode of their interaction with the G-4 structure, providing fundamental insights into the potential complexity of ligand/G-4 interactions and how they might influence gene expression (30).

Recognition of the biological significance of G-4 structures has put a new wave of interest in the search and development of G-4 interactive compounds. Targeting such secondary nucleic acid structures currently represents a novel, even though challenging, approach to anticancer drug design (12). Nonetheless, there are still several hurdles that need to be overcome before these peculiar compounds will be part of the currently available armamentarium of anticancer agents.

The high prevalence of G-4s in the human genome may raise concerns about the specificity of G-4-stabilising agents, even if the great structural variability of G-4 structures stands for their potential selective recognition. Nevertheless, it cannot be excluded that differences in promoter epigenetic modifications, cell proliferation-dependent transcriptional activity, and the presence of single nucleotide polymorphysms as well as protein crowding at the promoter level could account for a possible lower susceptibility to G-4-interacting agents of normal compared to cancer cells.

A point that needs to be urgently addressed deals with the in vivo existence of G-4 structures, which has been a matter of debate for decades. The possible presence of G-4 structures in vivo has been indirectly pointed out by the identification of a variety of proteins able to stabilize or promote the formation of as well as to destabilize or unwind the tetraplex DNA (41). Moreover, the very recent development of G-4 structure-directed antibodies that allow to quantitatively visualizing G-4 structures in human cells has undoubtedly represented a step of paramount importance in the G-4 research field $(42,43)$. Although a large amount of data has been provided concerning the G-4-mediated regulation of gene expression (44), direct evidence for the biological relevance of $\mathrm{G}-4 \mathrm{~s}$ in the cell context is still lacking. In this context, deep knowledge of the molecular mechanisms that facilitate the formation of G-4 structures (e.g., protein-nucleic acid interactions) will be instrumental in understanding the role of G-4s in living cells and for the identification of genes that effectively undergo a G-4 motif-dependent transcriptional control and not merely bear PQS. Filling the present gaps between the 
chemo-physical and the biological assays will help opening new avenues in the continuous fight against human diseases.

\section{Acknowledgements}

This study was supported by MIUR, Grant FIRB-Ideas RBID082ATK and by the University of Padova.

\section{References}

1. Lipps HJ and Rhodes D: G-quadruplex structures: in vivo evidence and function. Trends Cell Biol 19: 414-422, 2009.

2. Brooks TA, Kendrick S and Hurley L: Making sense of G-quadruplex and i-motif functions in oncogene promoters. FEBS J 277: 3459-3469, 2010.

3. Huppert JL: Structure, location and interactions of G-quadruplexes. FEBS J 277: 3452-3458, 2010.

4. Williamson JR, Raghuraman MK and Cech TR: Monovalent cation-induced structure of telomeric DNA: the G-quartet model. Cell 59: 871-880, 1989.

5. Balasubramanian S, Hurley LH and Neidle S: Targeting G-quadruplexes in gene promoters: a novel anticancer strategy? Nat Rev Drug Discov 10: 261-275, 2011.

6 . Eddy $\mathrm{J}$ and Maizels N: Conserved elements with potential to form polymorphic G-quadruplex structures in the first intron of human genes. Nucleic Acids Res 36: 1321-1333, 2008.

7. Huppert JL and Balasubramanian S: G-quadruplexes in promoters throughout the human genome. Nucleic Acids Res 35 406-413, 2007.

8. Bidzinska J, Cimino-Reale G, Zaffaroni N and Folini M: G-quadruplex structures in the human genome as novel therapeutic targets. Molecules 18: 12368-12395, 2013.

9. Brooks TA and Hurley LH: Targeting MYC Expression through G-Quadruplexes. Genes Cancer 1: 641-649, 2010.

10. Hanahan D and Weinberg RA: Hallmarks of cancer: the next generation. Cell 144: 646-674, 2011.

11. Palumbo SL, Ebbinghaus SW and Hurley LH: Formation of a unique end-to-end stacked pair of G-quadruplexes in the hTERT core promoter with implications for inhibition of telomerase by G-quadruplex-interactive ligands. J Am Chem Soc 131: 10878-10891, 2009.

12. Düchler M: G-quadruplexes: targets and tools in anticancer drug design. J Drug Target 20: 389-400, 2012.

13. Hurley LH: Secondary DNA structures as molecular targets for cancer therapeutics. Biochem Soc Trans 29: 692-696, 2001.

14. Kumar P, Yadav VK, Baral A, Kumar P, Saha D and Chowdhury S: Zinc-finger transcription factors are associated with guanine quadruplex motifs in human, chimpanzee, mouse and rat promoters genome-wide. Nucleic Acids Res 39: 8005-8016, 2011.

15. Rangan A, Fedoroff OY and Hurley LH: Induction of duplex to G-quadruplex transition in the c-myc promoter region by a small molecule. J Biol Chem 276: 4640-4646, 2001.

16. Sun D, Liu WJ, Guo K, et al: The proximal promoter region of the human vascular endothelial growth factor gene has a G-quadruplex structure that can be targeted by G-quadruplex-interactive agents. Mol Cancer Ther 7: 880-889, 2008.

17. Arola A and Vilar R: Stabilisation of G-quadruplex DNA by small molecules. Curr Top Med Chem 8: 1405-1415, 2008.

18. Petenzi M, Verga D, Largy E, et al: Cationic pentaheteroaryls as selective G-quadruplex ligands by solvent-free microwave-assisted synthesis. Chemistry 18: 14487-14496, 2012.

19. Collie GW, Promontorio R, Hampel SM, Micco M, Neidle S and Parkinson GN: Structural basis for telomeric G-quadruplex targeting by naphthalene diimide ligands. J Am Chem Soc 134: 2723-2731, 2012.

20. Di Antonio M, Doria F, Richter SN, et al: Quinone methides tethered to naphthalene diimides as selective G-quadruplex alkylating agents. J Am Chem Soc 131: 13132-13141, 2009.

21. Doria F, Nadai M, Folini M, et al: Hybrid ligand-alkylating agents targeting telomeric G-quadruplex structures. Org Biomol Chem 10: 2798-2806, 2012.

22. Gunaratnam M, de la Fuente M, Hampel SM, et al: Targeting pancreatic cancer with a G-quadruplex ligand. Bioorg Med Chem 19: 7151-7157, 2011.
23. Hampel SM, Sidibe A, Gunaratnam M, Riou JF and Neidle S: Tetrasubstituted naphthalene diimide ligands with selectivity for telomeric G-quadruplexes and cancer cells. Bioorg Med Chem Lett 20: 6459-6463, 2010.

24. Nadai M, Doria F, Di Antonio M, et al: Naphthalene diimide scaffolds with dual reversible and covalent interaction properties towards G-quadruplex. Biochimie 93: 1328-1340, 2011.

25. Livak KJ and Schmittgen TD: Analysis of relative gene expression data using real-time quantitative PCR and the 2(-Delta Delta C(T)) method. Methods 25: 402-408, 2001.

26. Greenfield NJ: Using circular dichroism collected as a function of temperature to determine the thermodynamics of protein unfolding and binding interactions. Nat Protoc 1: 2527-2535, 2006.

27. Kumar N, Basundra R and Maiti S: Elevated polyamines induce c-MYC overexpression by perturbing quadruplex-WC duplex equilibrium. Nucleic Acids Res 37: 3321-3331, 2009.

28. Kumar N, Patowary A, Sivasubbu S, Petersen M and Maiti S: Silencing c-MYC expression by targeting quadruplex in P1 promoter using locked nucleic acid trap. Biochemistry 47 : 13179-13188, 2008.

29. Borgognone M, Armas P and Calcaterra NB: Cellular nucleicacid-binding protein, a transcriptional enhancer of c-Myc, promotes the formation of parallel G-quadruplexes. Biochem J 428: 491-498, 2010.

30. Waller ZA, Sewitz SA, Hsu ST and Balasubramanian S: A small molecule that disrupts G-quadruplex DNA structure and enhances gene expression. J Am Chem Soc 131: 12628-12633, 2009.

31. Wang XD, Ou TM, Lu YJ, et al: Turning off transcription of the bcl-2 gene by stabilizing the bcl-2 promoter quadruplex with quindoline derivatives. J Med Chem 53: 4390-4398, 2010.

32. McLuckieKI, WallerZA,SandersDA, etal:G-quadruplex-binding benzo[a]phenoxazines down-regulate c-KIT expression in human gastric carcinoma cells. J Am Chem Soc 133: 2658-2663, 2011.

33. Hsu ST, Varnai P, Bugaut A, Reszka AP, Neidle S and Balasubramanian S: A G-rich sequence within the c-kit oncogene promoter forms a parallel G-quadruplex having asymmetric G-tetrad dynamics. J Am Chem Soc 131: 13399-13409, 2009.

34. Bejugam M, Sewitz S, Shirude PS, Rodriguez R, Shahid R and Balasubramanian S: Trisubstituted isoalloxazines as a new class of G-quadruplex binding ligands: small molecule regulation of c-kit oncogene expression. J Am Chem Soc 129: 12926-12927, 2007.

35. Rankin S, Reszka AP, Huppert J, et al: Putative DNA quadruplex formation within the human c-kit oncogene. J Am Chem Soc 127: 10584-10589, 2005.

36. Dai J, Dexheimer TS, Chen D, et al: An intramolecular G-quadruplex structure with mixed parallel/antiparallel $\mathrm{G}$-strands formed in the human BCL-2 promoter region in solution. J Am Chem Soc 128: 1096-1098, 2006.

37. DexheimerTS, Sun D and Hurley LH: Deconvoluting the structural and drug-recognition complexity of the G-quadruplex-forming region upstream of the bcl-2 P1 promoter. J Am Chem Soc 128: 5404-5415, 2006.

38. Orlotti NI, Cimino-Reale G, Borghini E, et al: Autophagy acts as a safeguard mechanism against G-quadruplex ligand-mediated DNA damage. Autophagy 8: 1185-1196, 2012.

39. Maizels N: G4 motifs in human genes. Ann NY Acad Sci 1267: 53-60, 2012.

40. González V and Hurley LH: The c-MYC NHE III(1): function and regulation. Annu Rev Pharmacol Toxicol 50: 111-129, 2010.

41. Sissi C, Gatto B and Palumbo M: The evolving world of protein-G-quadruplex recognition: a medicinal chemist's perspective. Biochimie 93: 1219-1230, 2011.

42. Biffi G, Di Antonio M, Tannahill D and Balasubramanian S: Visualization and selective chemical targeting of RNA G-quadruplex structures in the cytoplasm of human cells. Nat Chem 6: 75-80, 2014.

43. Biffi G, Tannahill D, McCafferty J and Balasubramanian S: Quantitative visualization of DNA G-quadruplex structures in human cells. Nat Chem 5: 182-186, 2013.

44. Tarsounas M and Tijsterman M: Genomes and G-quadruplexes: for better or for worse. J Mol Biol 425: 4782-4789, 2013.

45. Yadav VK, Abraham JK, Mani P,Kulshrestha R and Chowdhury S: QuadBase: genome-wide database of G4 DNA - occurrence and conservation in human, chimpanzee, mouse and rat promoters and 146 microbes. Nucleic Acids Res 36: D381-D385, 2008.

46. Kikin O, D'Antonio L and Bagga PS: QGRS Mapper: a web-based server for predicting G-quadruplexes in nucleotide sequences. Nucleic Acids Res 34: W676-W682, 2006. 